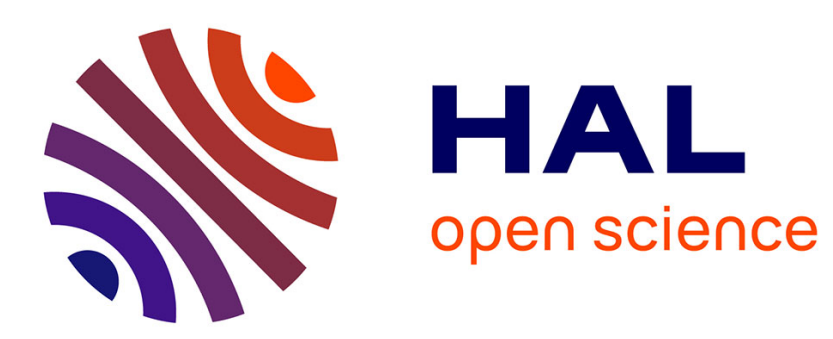

\title{
Structure, age, and tectonic evolution of the Gulf of Mexico
}

Andreína García-Reyes, Jérôme Dyment

\section{To cite this version:}

Andreína García-Reyes, Jérôme Dyment. Structure, age, and tectonic evolution of the Gulf of Mexico. Earth and Planetary Science Letters, 2022, 577, pp.117259. 10.1016/j.epsl.2021.117259 . insu03452882

\section{HAL Id: insu-03452882 \\ https://hal-insu.archives-ouvertes.fr/insu-03452882}

Submitted on 27 Nov 2021

HAL is a multi-disciplinary open access archive for the deposit and dissemination of scientific research documents, whether they are published or not. The documents may come from teaching and research institutions in France or abroad, or from public or private research centers.
L'archive ouverte pluridisciplinaire HAL, est destinée au dépôt et à la diffusion de documents scientifiques de niveau recherche, publiés ou non, émanant des établissements d'enseignement et de recherche français ou étrangers, des laboratoires publics ou privés. 
1 Structure, age, and tectonic evolution of the Gulf of Mexico

2

3 Andreína García-Reyes and Jérôme Dyment*

4 Université de Paris, Institut de physique du globe de Paris, CNRS, F-75005 Paris, France

5

$6 *$ Corresponding author: jdy@ipgp.fr

9 Abstract

10 The Gulf of Mexico is an isolated oceanic basin whose nature, structure and age are not fully

11 elucidated, mostly because seafloor spreading isochrons have not been identified in this basin

12 so far. We compiled and processed all publicly available marine magnetic data to produce a

13 new magnetic anomaly map of the Gulf of Mexico. This map reveals a fan-like set of

14 intermediate-wavelength $(>100 \mathrm{~km})$ magnetic anomalies related to seafloor spreading. Our

15 magnetic anomaly-based plate reconstructions (1) support a counterclockwise rotation of the

16 Yucatán Block around a pole located NW of Cuba, (2) accommodate the fracture zone trends

17 depicted by the gravity data, and (3) suggest that the Continent-Ocean Boundary lies

18 immediately south of the Houston magnetic anomaly, close to the shoreline, implying that

19 oceanic crust underlies a significant part of the Sigsbee salt province. Our attempt to identify

20 the intermediate wavelength anomalies by comparison with filtered Geomagnetic Polarity

21 Time Scales dates the onset of seafloor spreading before the Tithonian $(>150 \mathrm{Ma})$ and its

22 cessation at the Berriasian (140 Ma). 


\section{Introduction}

26 Most authors agree on the presence of oceanic crust within the Gulf of Mexico (hereafter

27 GoM), the location of the transition between oceanic and continental crust remains 28 controversial (e.g., Eagles et al., 2015). The kinematics of this isolated basin is crucial to 29 understand the tectonic evolution of America during the breakup of Pangea. As one of the 30 richest petroleum provinces of the world, it has been explored intensively for several decades 31 and imaged by countless seismic data. More recently, satellite-derived vertical gradient of 32 gravity (VGG) illuminated fracture zones in its western part (Bonvalot et al., 2012; Sandwell 33 et al., 2014). Gravity data interpretation remain unclear in some areas, preventing the 34 structure (and therefore the nature - oceanic or continental) of the crust to be unraveled. This 35 is the case in the northern GoM, where the gravity signal of thick salt and sediment deposits 36 overprint that of the underlying crust. Based on the Jurassic age (Bajocian to Oxfordian) of 37 this salt (Pindell et al., 2020) and the Late Jurassic-Cretaceous age of later sediments (e.g., 38 Galloway, 2008; Snedden et al., 2015; Lin et al., 2019), previous evolution models 39 considered that the GoM started to open during the Jurassic (Carey, 1958; Bullard et al., 40 1965; Pindell and Dewey, 1982; Hall et al., 1982; Schlager et al., 1984, Buffler and Sawyer, 41 1985; Ross and Scotese, 1988; Keppie and Keppie, 2014). The counter-clockwise rotation of 42 the Yucatán Block (e.g., Pindell and Dewey, 1982; Marton and Buffer, 1994) is confirmed by 43 paleomagnetic results (e.g., Molina-Garza et al., 1992). Such an opening would be 44 contemporaneous to that of the nearby Central Atlantic (Marzoli et al., 1999; Blackburn et al., 45 2013). However, despite an abundant data set, marine magnetic anomalies related to seafloor 46 spreading- which would provide the structure, the age, and therefore the evolution of the 47 GoM - remain elusive and debatable. Several authors (e.g., Nguyen et al., 2015; Pindell et 48 al., 2016; Lundin and Doré, 2017; Lin et al., 2019; Minguez et al., 2020) followed the VGG 49 interpretation of Sandwell et al. (2014) to locate the GoM fossil spreading center, transform 
50 faults, and continent-ocean boundary (COB). They present excerpts of the available global 51 magnetic anomaly maps but failed to recognize a regional magnetic anomaly pattern 52 supporting their interpretation.

53 In this paper, we present a new geophysical interpretation of the GoM based primarily on 54 marine magnetic anomaly data. The major differences between our and previous works can 55 be summarized in five points:

56 (1) We compiled, processed and reassessed all the available marine magnetic data in the 57 GoM. As a result, we derived a new, improved magnetic anomaly map of the GoM. This important effort allowed us to observe a symmetrical pattern of intermediate-wavelength magnetic anomalies that we ascribe to seafloor spreading in the basin.

(2) The location of the (main) fossil spreading center is primarily based on the interpretation of the new magnetic anomaly map and corresponds to the symmetry axis of the conjugate magnetic anomalies of the basin. This location differs from those from previous studies (Supplementary Figure S6). Although we agree with the interpretation of Sandwell et al. (2014) for the transform faults and fracture zones, we consider their two short segments of abandoned spreading axis in the southwestern GoM as reflecting local ridge jumps further substantiated by the spreading asymmetry seen from the magnetic anomaly interpretation. Conversely, the western part of the main fossil spreading axis constrained by the magnetic anomalies bears no VGG signature, because it is buried beneath the southern Sigsbee Salt Province and its gravity signature is hidden amongst the gravity signals of complex structures related to salt tectonics and/or sedimentation history.

(3) Unlike previous studies, we mostly use our new magnetic anomaly map (with the truncation of continental anomalies and presence of seafloor spreading anomalies), complemented by the VGG (with the shelf-break), to define the location of the COB in 
the study area. The location of our COB significantly differs from many previous interpretations in the northwestern GoM, off Texas and Louisiana. These previous interpretations cannot be reconciled with the observed magnetic anomalies.

(4) We attempt to date the observed magnetic anomalies by comparison with a filtered geomagnetic polarity time scale. Although not a classical approach, the lack of short wavelength magnetic anomalies on the available data offers no better option.

(5) As a consequence of these different interpretations, we present a new, consistent model for the opening of the GoM based on the new magnetic anomaly map. along marine tracks (Supplementary Figure S2). We calculated magnetic anomalies by

93 removing models of the Earth's internal magnetic field. To this end, we used the

94 Comprehensive Magnetic Model v.4 (CM4; Sabaka, 2004) for the time interval between 1960 and 2002.5, complemented by the IGRF-11 (Thébault et al., 2015) for data acquired outside

96 this time range. We performed internal and external leveling of the marine tracks to reduce

97 the misfit at the crossovers (see details in García-Reyes, 2018; Supplementary Table S1). We

98 complemented the map built with marine data with the WDMAM v. 2.0 (Lesur et al., 2016)

99 on land. We applied different filters in an attempt to unravel possible magnetic anomalies 

wavelengths $>100 \mathrm{~km}$ removed spurious effects from local short wavelength anomalies and artefacts and retains what we regard as the reliable spectral content. The resulting map

103 (hereafter named "intermediate wavelength magnetic anomaly map") is used in all 104 interpretations of this paper.

105 Although using reduced-to-the pole (RTP) magnetic anomalies, which unambiguously lie above their causative sources, would make interpretations and comparisons easier, we have no clear indication whether these anomalies are caused by induced or by remanent magnetization. In the latter case, computing RTP anomalies would require the direction of the remanent magnetization vector to be reliable. Because we lack constraints on this parameter, we preferred not to compute a RTP magnetic anomaly.

\section{From potential field data to plate motion model}

113 We inspected the pattern of the available gravity and marine magnetic data to identify

114 seafloor spreading features and the Continent-Ocean Boundary (COB) in the GoM. We 115 interpreted the magnetic anomalies and built a tectonic map of the basin by recognizing 116 conjugate anomalies with respect to a central magnetic anomaly that marks the extinct ridge 117 axis (Figure 1b). We used each pair of conjugate magnetic isochrons to calculate finite 118 rotations (pole and angle of rotation, Supplementary Table S2), from which we derived stage

119 rotations. We then constructed our plate evolution model for the opening of the GoM (Figure

120 2). We tried to account for both the interpreted magnetic anomalies and the fracture zones 121 observed on VGG (Figure 1).

122 Since only intermediate wavelength magnetic anomalies related to seafloor spreading could 123 be recognized, we lack precise isochrons determinations and cannot use the statistical method 124 of Chang (1988) for computing the finite rotation parameters. Instead, we approximated the 
125 interpreted fracture zones with small circles, determined great circles perpendicular to those

126 modelled fracture zones (simulating the projection of the rotation axis on a spherical shape),

127 and employed a best-fitting method to determine crossings of the great circles, i.e. possible

128 Euler poles (Morgan, 1968). We considered crossings as trial poles and kept those ones with

129 the higher statistical count. We produced flowlines with the selected poles, building segments

130 of small circles for each stage rotation poles, and compared them with the interpreted fracture

131 zones for validation (Figure 3; Supplementary Figure S5). We qualitatively compared

132 different sets of flowlines (built with different sets of rotation poles) with the interpreted FZs.

133 The COB shows a major contrast of density and magnetic properties in the crust and the

134 lithosphere. Therefore, we infer that it is located within a relatively narrow zone of high

135 gravity and magnetic gradients in the south and east of the GoM. Although they may not be

136 isochrons senso stricto, we reconstructed the conjugate COBs to determine rotation

137 parameters for the total closure of the GoM (Supplementary Table S2 and Supplementary

138 Figure S7).

\section{Age and Spreading rate}

141 We vainly tried to analyze the few well-oriented individual magnetic profiles for profile-to-

142 profile similarities and similarities to synthetic magnetic anomaly models. We therefore

143 confirm that the amount, resolution and quality of the available magnetic data in the GoM is

144 insufficient to attempt a detailed identification of marine magnetic anomalies within the

145 whole basin. Although this point needs additional data to be conclusively sorted out, we

146 suspect that short wavelength magnetic anomalies related to seafloor spreading may be absent

147 in the GoM for reasons that are developed below.

148 
149 We therefore attempted to date the seafloor by comparing the observed intermediate 150 wavelength anomalies to various filtered Geomagnetic Polarity Time Scales (GPTS). In order 151 to match the wavelength of the observed magnetic anomalies, each GPTS was filtered using 152 various Gaussian filters to account for a range of different possible spreading rates 153 (Supplementary Figure S11). The filtered polarity time scales were compared to five 154 magnetic profiles extracted from the intermediate wavelength magnetic anomaly map (see 155 above) along flowlines to attempt identifying the magnetic isochrons (Figure 4). Different 156 possible solutions were considered with respect to the available geological data and the most 157 geologically reasonable interpretation was selected, from which ages were ascribed to the anomalies (Supplementary Table S5; Supplementary Figure S13). This exercise implicitly

159 assumes that no major change of angular velocities occurred during the opening of the basin.

160 We calculated spreading rate and asymmetry along each flowline (Supplementary Tables S3 161 and S4; Supplementary Figures S9 and S10.

163 A New Magnetic Map of the Gulf of Mexico

164 Unlike most of the previous magnetic maps for the area (e.g., Bankey et al., 2002) but in 165 agreement with a recent dense aeromagnetic map of the southern GoM (Pindell et al., 2016), 166 our new magnetic anomaly map displays a group of East-West elongated intermediate 167 wavelength and low amplitude $(-50-+50 \mathrm{nT})$ anomalies. The group is made of three positive 168 and four negative anomalies. The central positive anomaly is the longest one and extends 169 over $\sim 1500 \mathrm{~km}$, whereas the outer positive anomalies are $\sim 1000 \mathrm{~km}$ long. The anomalies on 170 both sides of the central one appear to be symmetrical at first order, with similar lateral 171 variations in extent, width, and amplitude. Altogether they define a magnetic fan-like 172 structure that we consider reflects the seafloor spreading evolution of the GoM. Aside from 173 this oceanic domain we identify four distinct magnetic domains surrounding the GoM: the 
174 conjugate Yucatán (1, see Supplementary Figure S7) and Florida (2) cratonic blocks show 175 strong anomalies of relatively long wavelength that a proper reconstruction aligns, 176 emphasizing their pre-rift origin, only locally erased by the later Chicxulub impact at 65 Ma.

177 The Trans Mexican volcanic belt (3) exhibits moderate amplitude and shorter wavelength 178 anomalies. The basins fringing Louisiana and Texas, the Western Gulf Coast Basin and the 179 Texas-Louisiana-Mississippi Salt Basin (4) display an East-West elongated positive magnetic 180 anomaly that was interpreted as intracontinental by previous workers (Houston magnetic 181 anomaly, after Hall et al., 1990).

\section{The Continent-Ocean Boundary}

184 The free-air gravity anomaly and its vertical gradient often display a sharp signal at the shelf185 break, which sometimes corresponds to the COB but may also be shifted oceanward 186 depending on the pattern of sediment accumulation and possible underplating or post-rift 187 magmatism. The magnetic anomaly is also not always conclusive, the COB being sometimes 188 - but not systematically - marked by a magnetic anomaly corresponding to synrift volcanic 189 activity. South and Northeast of the GoM (domains 1 and 2), we inferred the COB from both 190 the sharp gradients of magnetic anomalies and vertical gradients of gravity, which show a

191 good agreement (Figure 1). This inference is supported by seismic data (e.g., Christeson et 192 al., 2014). In the western GoM, the signature of fracture zones in gravity data confirms the 193 oceanic nature of its crust (Sandwell et al., 2014, Figure 1c and d). In this area (domain 3), 194 we interpret the Eastern Mexico Transform Margin (also known as Tamaulipas-Golden Lane195 Chiapas Transform) as the COB, as proposed by previous authors (e.g., Nguyen et al., 2015). 196 The location of the COB in the north-western and north-central parts of the GoM (domain 4) 197 has been more widely discussed due to the ambiguous signature of their potential field and 198 seismic data. The gravity signal of the underlying crust is obscured by the thick sediments 
199 (including evaporites) of the Sigsbee salt province (Supplementary Figure S4). Seismic 200 reflection and refraction data there suggest a progressive thinning of the crust oceanward 201 (e.g., Profiles GUMBO 1 off Texas; Van Avendonk et al., 2015; and GUMBO 2 off 202 Louisiana; Eddy et al., 2018) without a sharp transition that might unambiguously be 203 interpreted as the COB, as in the eastern GoM (e.g., Profile GUMBO 3 off Alabama; Eddy et 204 al., 2014; and GUMBO 4 off Florida; Christeson et al., 2014). Our interpretation of the COB 205 does therefore not contradict the GUMBO seismic data. Conversely, the symmetry of the fan206 like anomalies in the GoM oceanic domain requires the COB in domain 4 to lie immediately 207 south of the Houston magnetic anomaly, close to the shoreline. As a consequence, the 208 northernmost anomaly related to seafloor spreading is found $\sim 300 \mathrm{~km}$ north of the southern 209 boundary of the Sigsbee salt province, implying that oceanic crust underlies a significant part 210 of this province.

211 We confirmed the location of the COB in the controversial areas by attempting to juxtapose 212 the conjugate COB and close the GoM (Supplementary Figure S7). This is not a plate 213 reconstruction sensu stricto, as the COB is not necessarily an isochron. The observed fan-like 214 shape of the magnetic anomalies implies that the pole of the Euler rotation closing the GoM 215 lies NW of Cuba, immediately south of Florida and east of Yucatán, as suggested by previous 216 studies (e.g., Pindell, 1985; Bird and Burke, 2006; among others). We achieved the closure of 217 the GoM by juxtaposing the conjugate COBs where they are both well constrained, off the 218 North Coast of Yucatán and the West Coast of Florida, respectively. The best-fitting rotation 219 has a pole at $85.18^{\circ} \mathrm{W}, 23.99^{\circ} \mathrm{N}$ and an angle of $59^{\circ}$ (geocentric latitude). Magnetics show a 220 good correspondence between reconstructed Yucatán and Florida, with continuous magnetic 221 anomalies across the margin (Supplementary figure S7). Further West, the Houston magnetic 222 anomaly and a strong parallel magnetic high on the Yucatán Block may mark early 223 magmatism on the passive margin. 


\section{The Oceanic Basin}

226 In this section, we focus on the oceanic basin to further investigate the GoM plate tectonic 227 history. The tectonic features available to attempt plate reconstructions are (1) the COB as 228 previously defined from gravity and magnetics; (2) the few fracture zones identified on the 229 VGG in the west GoM (Sandwell et al., 2014); and (3) conjugate magnetic anomalies.

230 We identified pairs of conjugate anomalies and the fossil ridge axis within the fan-like 231 structure observed on the magnetic anomaly map (Figures 1 and 3). The axis of symmetry is 232 a positive anomaly, marked GoM1, that extends from East to West along the whole oceanic 233 basin and marks the fossil spreading center. It is flanked on each side by a pair of roughly 234 symmetrical positive anomalies marked GoM2. These anomalies are observed off the 235 Mexican Coast in the Western GoM and abut the COB off Florida at $\sim 87^{\circ} \mathrm{W}$ and off Yucatán 236 at $\sim 89^{\circ} \mathrm{W}$. It is worth noting that conjugate anomalies abut conjugate parts of the COB. The 237 truncation of the older anomalies to the East suggests that the seafloor spreading propagated 238 from West to East in this area, in relation to the progressively slower relative plate motion 239 toward the rotation pole.

240 The conjugate magnetic anomalies constrain the detailed plate tectonic evolution of the GoM.

241 The GoM1 and GoM2 positive anomalies offer three isochrons, namely the older side of 242 GoM1 (GoM1o) and the younger and older sides of GoM2 (GoM2y and GoM2o, 243 respectively), to attempt plate reconstructions. However, the GoM1o isochrons are too close 244 to each other to provide any meaningful results. We therefore limit our magnetic 245 reconstructions to GoM2y and GoM2o. Unlike classical plate reconstructions based on 246 individual magnetic anomaly identification on individual profiles, our isochrons are 247 interpreted from intermediate wavelength anomalies on gridded data. Therefore, instead of 248 attempting to use the whole isochrons, we preferred to match specific features recognized on 10 
249 both conjugate isochrons such as fracture zone offsets to compute the rotation parameters

250 (Figure 3). The resulting plate reconstructions are shown in Figure 2.

251 We computed stage rotations on both flanks for the GoM2o-GoM2y interval from the finite 252 rotations reconstructing conjugate anomalies GoM2y and GoM2o, respectively. The finite 253 and stage poles all lie between Yucatán and Florida (Figure 3). Finite and stage rotation 254 parameters are given in Supplementary Table S2. The flow lines built from the resulting 255 model are in reasonable agreement with the fracture zone trend observed on the VGG in the 256 western GoM (Figure 3; Supplementary Figure S5) and describes the seafloor spreading 257 evolution of the GoM after the age of anomaly GoM2o.

258 The eastwards truncation of magnetic anomaly GoM2 at the COB confirms that the COB is 259 not an isochron. Therefore, the total closure reconstruction should only be regarded as an 260 exercise to evaluate the respective initial location of the two continental blocks and the 261 continuity of gravity and magnetic features across their passive margins. Clearly, these 262 margins experienced stretching and deformation when seafloor spreading was already 263 occurring to the west, and therefore an accurate initial reconstruction should take this 264 deformation into account, which is out of the scope of this paper. As a consequence, our total 265 closure rotation parameters do not predict a spreading direction compatible with the observed 266 fracture zones in the Western GoM (Supplementary Figure S8).

267 Two distinct tectonic phases are therefore recognized for the opening of the GoM. In the first 268 phase, the western part of the Gulf was experiencing seafloor spreading whereas the eastern 269 part was still under continental rifting. The breakup progressively propagated eastward. No 270 meaningful reconstruction parameters could be derived for this phase due to the lack of 271 appropriate isochrons. The second phase started once breakup was achieved along most of the 272 basin, at the age of GoM2o. A steadier regime of seafloor spreading established, in which the 273 available isochrons allow us to distinguish two sets of stage rotation parameters for GoM2o11 
274 GoM2y and GoM2y-GoM1y. These rotation poles are closely bunched together and would

275 probably be statistically indistinguishable if statistical plate reconstruction methods could be 276 applied in the GoM.

\section{Dating the intermediate-wavelength magnetic anomalies}

279 Our plate tectonic model for the evolution of the GoM still lacks an essential aspect: neither

280 the onset of seafloor spreading nor isochrons GoM2 and GoM1 have been ascribed an age so 281 far. For reasons that are either related to the data distribution and quality, or to the processes 282 of oceanic crust emplacement in young, isolated basins with thick sediments and evaporites 283 (e.g., Dyment et al., 2013; see below), the classical short-wavelength magnetic anomalies 284 associated to seafloor spreading could not be recognized in the GoM. We compare the 285 sequence of observed intermediate wavelength anomalies with filtered GPTS in an attempt to 286 recognize and therefore date these anomalies. Five representative profiles were extracted 287 from the anomaly map following flowlines defined by the rotation parameters. Considering 288 the uncertainties on the M-series GPTS, we carried out the same procedure on four published 289 GPTS (Kent and Gradstein, 1986; Gradstein and Ogg, 1996; Tominaga and Sager, 2010; 290 Malinverno et al., 2012, used in Figure 4) to ensure that the result does not depend on 291 peculiarities of a given time scale (Supplementary Figure S11).

292 Global plate reconstructions and apparent polar wander models suggest that the GoM opened 293 at about $20^{\circ} \mathrm{N}$ (van Hinsbergen et al., , 2015). Assuming that it was formed at the Equator 294 along an approximately E-W spreading center and observed at the same location predicts 295 magnetic anomalies centered on their causative source with normal polarity generating a 296 negative anomaly and reversed polarity a positive anomaly (i.e., skewness $=180^{\circ}$ ). We first 297 adopt these simplifying assumptions and, to take into account this effect, we inverted the 298 filtered GPTS before attempting to identify the observed intermediate wavelength anomalies. 
299 We discuss the effect of more realistic paleo- and present latitudes and spreading center

300 directions in Supplementary Figure S12. Although the skewness of the observed intermediate

301 wavelength magnetic anomalies remains an elusive parameter, adopting more realistic

302 assumptions does not affect our interpretation but results in a 50 to $100 \mathrm{~km}$ shift of the fossil

303 spreading center and isochrons southward.

304 Our best fit between the inverted filtered GPTS and the observed profile, obtained for all 305 tested GPTSs, identifies the high of intermediate magnetic anomaly GoM1 with Chron M17r 306 and the high of GoM2 with Chrons M22r and M23r (Figure 4; Supplementary Figure S13).

307 We acknowledge that other acceptable solutions with different spreading rates and ages may

308 be obtained but consider this solution to be the most geologically plausible, both for the

309 predicted spreading rates and the age of seafloor spreading onset and demise. If correct, this

310 model predicts the onset of seafloor spreading in the GoM before the Tithonian and the

311 cessation of seafloor spreading at the end of the Berriasian. These ages are consistent with

312 geological studies of both conjugate margins (e.g., Stern and Dickinson, 2010; Barboza-

313 Gudino et al., 2012; Marton and Buffler, 2016). The analysis of seismic profiles linking

314 stratigraphy from wells on the Florida platform to the fossil spreading center in the Eastern

315 GoM confirms the Berriasian age of the spreading cessation (Lin et al., 2019).

\section{Discussion}

319 The finite and stage rotation poles that describe the relative plate motions for the origin of the

320 GoM are all located in the close vicinity of the eastern tip of the oceanic basin, as suggested

321 by the fan-like shape of the observed magnetic anomalies and in agreement with previous 322 studies (e.g., Pindell et al., 1985; Bird and Burke, 2006; among others). Spreading rates 323 therefore increase rapidly westward across the basin. On average, they vary from less than 20 
$324 \mathrm{~km} / \mathrm{Myr}$ in the East to about $50 \mathrm{~km} / \mathrm{Myr}$ in the West, i.e. from slow (and probably ultraslow

325 in the easternmost tip of the oceanic basin) to fast spreading (Supplementary Figure 9 and

326 Supplementary Table 3). The magnetic anomaly model presented in Figure 4 is valid for the

327 fast to slow spreading rates of the Western and Central GoM, but it may not be suitable for

328 the Easternmost GoM, where ultraslow spreading rates are expected and more drastic filters

329 would have to be applied to the GPTS to adequately model the observed anomalies. The

330 interpretation of marine magnetic anomalies in ultraslow spreading areas is a difficult

331 exercise and the available data do not allow further elaboration on this matter.

\section{- Asymmetry and abandoned spreading segments}

334 A more detailed appraisal of the magnetic anomaly map reveals spreading asymmetry in the

335 basin. Two maps and tables are presented, showing the total asymmetry (Supplementary

336 Figure 10a and Supplementary Table S4) and the stage by stage asymmetry (Supplementary

337 Figure 10b and Supplementary Table S4). The stage by stage asymmetry shows quite a large 338 scatter with no systematic trends, especially for the shorter GoM2o-GoM2y stage. This

339 reflects the increasing relative weight of the uncertainties on the isochron location with

340 respect to the stage duration. Conversely, the total symmetry shows four distinct corridors

341 with systematic asymmetry. Flowlines 1-2 show asymmetry to the benefit of the northern

342 flank (corridor A), flowlines 5-10 of the southern flank (corridor B), flowlines 13-14 of the 343 northern flank (corridor C), and flowlines 17-19 of the southern flank (corridor D). The effect

344 of this asymmetry is to progressively reshape the ridge axis, as the arc-shape described by the

345 COBs in the Western and Central GoM progressively evolved to the more sinuous fossil 346 ridge axis. The strongest asymmetry, more than $60 \%$, is observed in corridor B and is most 347 probably accommodated by ridge jumps, explaining the two short segments of abandoned 348 spreading axis left on the southern flank in the Western GoM and identified on the VGG 14 
350 lie in an anomalously wide magnetic anomaly which reflects a northward ridge jump and the abandonment of a fossil axis on the southern flank.

\section{- Why are short wavelength magnetic anomalies not observed in the GoM?}

354 The reason why short-wavelength magnetic anomalies have not been depicted in the GoM so 355 far is still uncertain. The paucity of marine data and/or their inadequacy to define lineated 356 short-wavelength anomalies may be a reason. However, proprietary aeromagnetic surveys exist over parts of the GoM (e.g., Pindell et al., 2016). We suspect that the $3 \mathrm{~km}$-interval (EW lines) and $9 \mathrm{~km}$-interval (NS lines) of the proprietary aeromagnetic survey flown some $15 \mathrm{~km}$ or less above the basement (Pindell et al., 2016) would have allowed the depiction of anomalies of wavelength shorter than $100 \mathrm{~km}$ if such anomalies existed. However, we cannot exclude that the aeromagnetic map published by Pindell et al. (2016) was degraded to a lower resolution for the purpose of publication, although this is not mentioned in the paper.

The other possibility is that such short wavelength anomalies do not actually exist. Two scenarios may explain their absence. In the first one, abundant post-accretion sedimentation may have erased the magnetic anomalies due to the extrusive basalt titanomagnetite (Curie temperature $\sim 200^{\circ} \mathrm{C}$ ) by reheating and partial thermal demagnetization, as suggested by Levi and Riddihough. (1986) for the Gulf of California, the Gulf of Aden, and the northern Red Sea, and by Granot and Dyment (2019) for the South Atlantic margin off Argentina. In the second one, abundant syn-accretion sedimentation - and the presence of mobile evaporitic

370 deposits - would have inhibited the formation of the extrusive basalt layer, replaced by 371 intrusive (and therefore less magnetic) sills, as suggested by Dyment et al. (2013) for most of 372 the Red Sea. In both instances, the observed intermediate-wavelength magnetic anomalies are 
373 caused by the deeper crustal layers whose magnetic mineral, magnetite, has a higher Curie

374 temperature $\left(\sim 580^{\circ} \mathrm{C}\right)$.

375 Solving this pending issue requires access to the existing dense aeromagnetic surveys over

376 the GoM and/or the acquisition of new marine magnetic anomaly profiles along flowlines.

\section{Conclusion}

379 Our compilation and processing of marine magnetic anomalies allowed us to identify 380 intermediate-wavelength magnetic anomalies related to seafloor spreading in the Gulf of 381 Mexico (GoM). We identified the fossil ridge axis and a pair of conjugate positive anomalies 382 and deciphered the GoM plate tectonic history from the magnetic isochrons, fracture zones as 383 imaged by gravity, and the COB depicted from both gravity and magnetics. The fan-shape 384 structure of the observed magnetic anomalies supports a counterclockwise rotation of the 385 Yucatán Block with respect to a pole located NW of Cuba. The older magnetic anomalies 386 abut on the $\mathrm{COB}$, suggesting that oceanization propagated from West to East. The 387 observation of seafloor spreading magnetic anomalies on the offshore part of the Sigsbee Salt 388 Province implies that it is underlain by oceanic crust, as is the offshore part of the Campeche 389 Salt Province. Our plate reconstruction model suggests two stages of evolution: the first one 390 showed continental rifting in the East and seafloor spreading in the West, the latter 391 propagating eastward at the expenses of the former; and the second one, after completion of 392 the breakup, showing seafloor spreading along the entire GoM. Filtering the geomagnetic 393 polarity time scale allowed us to tentatively date the observed anomalies (and therefore the 394 second stage): seafloor spreading onset in the GoM predates the Tithonian (>150 Ma) and 395 stopped during the Berriasian (140 Ma). As reflected by the proximity of the rotation poles, 396 strong spreading rate variations are observed from ultraslow in the easternmost GoM to fast 
397 in the West, where the measured spreading asymmetry confirms our interpretation of short,

398 abandoned spreading segments.

400 Data availability. We downloaded marine total magnetic field measurements from the 401 National Center for Environmental Information (formerly National Geophysical Data Center; 402 www.ngdc.noaa.gov/mgg/geodas/trackline.html). Magnetic anomalies on land are from the 403 World Digital Magnetic Anomaly Map (Dyment et al., 2015; Lesur et al., 2016; wdmam.org). 404 Vertical gradients of gravity are available from the Scripps Institution of Oceanography, 405 University of California in San Diego (Sandwell et al., 2014; topex.ucsd.edu). A low406 resolution version of the magnetic anomalies supporting the findings of this study will be 407 incorporated in the WDMAM version 2.1. The full resolution version is available from the 408 corresponding author upon request.

410 Acknowledgements.

411 AGR has been supported by a PhD scholarship of Fundayacucho and Campus France and 412 additional support from IPGP, as well as a Postdoctoral Fellowship of Programme PAUSE.

413 We thank all scientists and crews who collected the marine geophysical data used in this 414 study. This is IPGP contribution xxx. 


\section{References}

1. Bankey, V., Cuevas, A., Daniels, D., Finn, C. A., Hernandez, I., Hill, P., Kucks, R., Miles, W., Pilkington, M., Roberts, C., Roest, W., Rystrom, W., Shearer, S., Snyder, S., Sweeney, R., Velez, J., Philips, J.D., Ravat, D. (2002). Digital data grids for the magnetic anomaly map of North America. U.S. Geological Survey Open-File Report 02-414, U.S. Geological Survey Denver Colorado USA.

2. Barboza-Gudino, J.R., R.S. Molina-Garza, and T.E. Lawton (2012). Sierra de Catorce: Remnants of the ancient western equatorial margin of Pangea in central Mexico, in J.J. Aranda-Górner, G. Tolsan, and R.S. Molina-Gana, eds., The Southern Cordillera and Beyond: Geological Society of America Field Guide 25. p. 1-18, https://doi.org/10.1130/2012.0025(01).

3. Bird, D., and Burke, K. (2006). Pangea breakup: Mexico, Gulf of Mexico, and Central Atlantic Ocean. SEG Technical Program Expanded Abstracts, 1013-1017a, https://doi.org/10.1190/1.2369685.

4. Blackburn, T. J., Olsen, P. E., Bowring, S. A., McLean, N. M., Kent, D. V., Puffer, J., McHone, G., Rasbury, E. T., and Et-Touhami, M. (2013). Zircon U-Pb geochronology links the end-Triassic extinction with the Central Atlantic Magmatic Province. Science, 340(6135):941-945, https://doi.org/10.1126/science.1234204.

5. Bonvalot, S., Balmino, G., Briais, A., Kuhn, M., Peyrefitte, A., Vales, N., Biancale, R., Gabalda, G., Moreaux, G., and Reinquin, F. (2012). World Gravity Map, 1:50000000 (map). BGI-CGMW-CNES-IRD, https://doi.org/s00190-011-0533-4.

6. Buffler, R. T., and Sawyer, D. S. (1985). Distribution of crust and early history, Gulf of Mexico basin. Gulf Coast Association of Geological Societies Transactions, 35:333-344, https://doi.org/10.1306/AD462C9F-16F7-11D7-8645000102C1865D. 
7. Bullard, E., Everett, J. E., and Smith, A. G. (1965). The fit of the continents around the Atlantic. Phil. Trans. R. Soc. Lond. A, 258(1088):41-51, https://doi.org/10.1098/rsta.1965.0020.

8. Carey, S. W. (1958). Continental Drift, a Symposium: Being a Symposium on the Present Status of the Continental Drift Hypothesis. Held in the Geology Department of the University of Tasmania in March, 1956, volume 2. Geology Department, University of Tasmania.

9. Chang, T. (1988). Estimating the relative rotation of two tectonic plates from boundary crossings. Journal of the American Statistical Association, 83(404):11781183, https://doi.org/10.1080/01621459.1988.10478717.

10. Christeson, G., Van Avendonk, H., Norton, I., Snedden, J., Eddy, D., Karner, G., and Johnson, C. (2014). Deep crustal structure in the eastern Gulf of Mexico. Journal of Geophysical Research: Solid Earth, 119(9):6782-6801, https://doi.org/10.1002/2014JB011045.

11. Dyment, J., Tapponnier, P., Afifi, A. M., Zinger, M. A., Franken, D., and Muzaiyen, E. (2013). A new seafloor spreading model of the Red Sea: magnetic anomalies and plate kinematics. Abstract T21A-2512 presented at 2013, Fall Meeting, AGU, San Francisco, CA, 9-13 December.

12. Dyment, J., Choi, Y., Hamoudi, M., Lesur, V., and Thébault, E. (2015). Global equivalent magnetization of the oceanic lithosphere. Earth and Planetary Science Letters, 430:54-65, https://doi.org/10.1016/j.eps1.2015.08.002.

13. Eagles, G., Pérez-Díaz, L., Scarselli, N. (2015). Getting over continent ocean boundaries. Earth-Science Reviews, 151:244-265, ISSN 0012-8252, https://doi.org/10.1016/j.earscirev.2015.10.009. 
14. Eddy, D. R., Van Avendonk, H. J. A., Christeson, G. L., Norton, I. O., Karner, G. D., Johnson, C. A., and Snedden, J. W. (2014). Deep crustal structure of the northeastern Gulf of Mexico: Implications for rift evolution and seafloor spreading, J. Geophys. Res. Solid Earth, 119: 6802-6822, https://doi:10.1002/2014JB011311.

15. Eddy, D. R., Van Avendonk, H. J., Christeson, G. L., and Norton, I. O. (2018). Structure and origin of the rifted margin of the northern Gulf of Mexico. Geosphere, 14 (4):1804-1817, https://doi.org/10.1130/GES01662.1.

16. Galloway, W. (2008). Chapter 15 Depositional Evolution of the Gulf of Mexico Sedimentary Basin. Editor(s): Andrew D. Miall, Sedimentary Basins of the World, Elsevier, 5:505-549, ISSN 1874-5997, ISBN 9780444504258, https://doi.org/10.1016/S1874-5997(08)00015-4.García-Reyes, A. (2018). Magnetic anomalies and plate tectonic history of the Caribbean plate and the Gulf of Mexico (Doctoral dissertation, Université Sorbonne Paris Cité). https://tel.archivesouvertes.fr/tel-02496674.

17. Gradstein, F., and Ogg, J. (1996). Geological time scale for the Phanerozoic. Episodes, 19(1-2):3-6, https://doi.org/10.18814/epiiugs/1996/v19i1.2/002.

18. Granot, R., and Dyment, J. (2019). The influence of post- accretion sedimentation on marine magnetic anomalies. Geophysical Research Letters, 46:4645-4652. https://doi.org/10.1029/2019GL082265.

19. Hall, D. J., Cavanaugh, T. D., Watkins, J. S., and McMillen, K. J. (1982). The Rotational Origin of the Gulf of Mexico Based on Regional Gravity Data: Rifted Margins: Field Investigations of Margin Structure and Stratigraphy. AAPG memoir, 34:115-126, https://doi.org/10.1306/M34430. 
20. Hall, D. J. (1990). Gulf Coast-East Coast magnetic anomaly I: Root of the main, crustal decollement for the Appalachian-Ouachita orogen. Geology, 18(9):862-865, https://doi.org/10.1130/0091-7613(1990)018<0862:GCECMA>2.3.CO;2.

21. Kent, D. V., and Gradstein, F. M. (1986). A Jurassic to recent chronology. The Geology of North America, 1000:45-50, https://doi.org/10.1130/DNAG-GNA-M.45.

22. Keppie, D. F., and Keppie, J. D. (2014). The Yucatan, a Laurentian or Gondwanan fragment? Geophysical and palinspastic constraints. International Journal of Earth Sciences, 103(5):1501-1512, https://doi.org/10.1007/s00531-013-0953-x.

23. Lesur, V., Hamoudi, M., Choi, Y., Dyment, J., and Thébault, E. (2016). Building the second version of the World Digital Magnetic Anomaly Map (WDMAM). Earth, Planets and Space, 68(1):1-13, https://doi.org/10.1186/s40623-016-0404-6.

24. Levi, S., and Riddihough, R. (1986). Why are marine magnetic anomalies suppressed over sedimented spreading centers. Geology, 14 (8): 651-654. https://doi.org/10.1130/0091-7613(1986)14<651:WAMMAS>2.0.CO;2

25. Lin, P., Bird, D.E., and Mann, P. (2019). Crustal structure of an extinct, late Jurassicto-earliest Cretaceous spreading center and its adjacent oceanic crust in the eastern Gulf of Mexico. Mar Geophys Res, 40:395-418, https://doi.org/10.1007/s11001-019$\underline{09379-5 .}$

26. Lundin, E.R., and Doré, A.G. (2017) The Gulf of Mexico and Canada Basin: Genetic Siblings on Either Side of North America. GSA Today, 27(1):4-11, https://doi.org/10.1130/GSATG274A.1.

27. Malinverno, A., Hildebrandt, J., Tominaga, M., and Channell, J. E. (2012). Msequence geomagnetic polarity time scale (MHTC12) that steadies global spreading rates and incorporates astrochronology constraints. Journal of Geophysical Research: Solid Earth, 117(B6), https://doi.org/10.1029/2012JB009260. 
28. Marton, G., and Buffler, R. T. (1994). Jurassic reconstruction of the Gulf of Mexico Basin. International Geology

Review,

36(6):545-586, https://doi.org/10.1080/00206819409465475.

29. Marton, G., and Buffler, R. T. (2016). Jurassic-Cretaceous Tectonic Evolution of the Southeastern Gulf of Mexico, Constrains on the Style and Timing of Gulf of Mexico Exhibition, Cancun, Mexico, September 6-9, 2016.

30. Marzoli, A., Renne, P. R., Piccirillo, E. M., Ernesto, M., Bellieni, G., and De Min, A. (1999). Extensive 200-million-year-old continental flood basalts of the Central Atlantic Magmatic Province. Science, 284(5414):616-618, https://doi.org/10.1126/science.284.5414.616.

31. Minguez, D., Gerald Hensel, E., Johnson, E. (2020). A fresh look at Gulf of Mexico tectonics: Testing rotations and breakup mechanisms from the perspective of seismically constrained potential-fields modeling and plate kinematics. Interpretation, 8:4, SS31-SS45, https://doi.org/10.1190/INT-2019-0256.1.

32. Molina-Garza, R. S., Van Der Voo, R. O. B., and Urrutia-Fucugauchi, J. (1992). Paleomagnetism of the Chiapas Massif, southern Mexico: Evidence for rotation of the Maya Block and implications for the opening of the Gulf of Mexico. Geological Society of America Bulletin, 104(9):1156-1168, https://doi.org/10.1130/00167606(1992)104<1156:POTCMS>2.3.CO;2.

33. Nguyen, L., and Mann, P. (2015). Gravity and magnetic constraints on the Jurassic opening of the oceanic Gulf of Mexico and the location and tectonic history of the Western Main transform fault along the eastern continental margin of Mexico. Interpretation, 4(1), SC23-SC33, https://doi.org/10.1190/INT-2015-0110.1. 
34. Pindell, J. and Dewey, J. F. (1982). Permo-Triassic reconstruction of western Pangea and the evolution of the Gulf of Mexico/Caribbean region. Tectonics, 1(2):179-211, https://doi.org/10.1029/TC001i002p00179.

35. Pindell, J. L. (1985). Alleghenian reconstruction and subsequent evolution of the Gulf https://doi.org/10.1029/TC004i001p00001.

36. Pindell, J., Miranda, C., Ceron, A., and Hernandez, L. (2016). Aeromagnetic map constrains Jurassic-Early Cretaceous synrift, break up, and rotational seafloor spreading history in the Gulf of Mexico. In Mesozoic of the Gulf Rim and Beyond: New Progress in Science and Exploration of the Gulf of Mexico Basin. 35th Annual Gulf Coast Section SEPM Foundation Perkins-Rosen Research Conference, GCS SEPM Foundation, Houston, TX, USA, 123-153, https://doi.org/10.5724/gcs.15.35.0123.

37. Pindell, J., Villagómez, D., Molina-Garza, R., Graham, R. and Weber, B. (2020). A revised synthesis of the rift and drift history of the Gulf of Mexico and surrounding regions in the light of improved age dating of the Middle Jurassic salt. Geological Society, London, Special Publications, 504:29-76, 1 October 2020, https://doi.org/10.1144/SP504-2020-43.

38. Ross, M. I., and Scotese, C. R. (1988). A hierarchical tectonic model of the Gulf of Mexico and Caribbean region. Tectonophysics, 155(1-4):139-168, https://doi.org/10.1016/0040-1951(88)90263-6.

39. Sabaka, T., Olsen, N., and Purucker, M. E. (2004) Extending comprehensive models of the Earth's magnetic field with Ørsted and CHAMP data. Geophysical Journal International, 159(2):521-547, https://doi.org/10.1111/j.1365-246X.2004.02421.x. 
40. Sandwell, D. T., Müller, R. D., Smith, W. H., Garcia, E., and Francis, R. (2014). New global marine gravity model from CryoSat-2 and Jason-1 reveals buried tectonic structure. Science, 346(6205):65-67, https://doi.org/science.1258213. 41. Schlager, W., Buffler, R. T., Angstadt, D., Bowdler, J. L., COTILlON, P., Dallmeyer, R. D., Halley, R. B., Kinoshita, H., Magoon, L. B. III, McNulty, C. L., Patton, J. W., Pisciotto, K. A., Premoli-Silva, I., Suarez, O. A., Testarmata, M. M., Tyson, R. V., and Watkins, D. K. (1984). Deep Sea Drilling Project Leg 77: Southeastern Gulf of Mexico. Geological Society of America Bulletin, 95:226-236, https://doi.org/10.1130/0016-7606(1984)95<226:DSDPLS>2.0.CO;2.

42. Schouten, H., and Klitgord, K. D. (1994). Mechanistic solutions to the opening of the Gulf of Mexico. Geology, 22(6):507-510, https://doi.org/10.1130/00917613(1994)022<0507:MSTTOO >2.3.CO;2.

43. Snedden, J.W., Virdell, J., Whiteaker, T.L., Ganey-Curry, P. (2015) A basin-scale perspective on Cenomanian-Turonian (Cretaceous) depositional systems, greater Gulf of Mexico (USA). Interpretation, 4(1):SC1-SC22. doi: https://doi.org/10.1190/INT$\underline{2015-0082.1 .}$.

44. Stern, R. J., and Dickinson, W. R. (2010) The Gulf of Mexico is a Jurassic backarc basin, Geosphere, 6(6):739-754, https://doi.org/10.1130/GES00585.1.

45. Tominaga, M., and Sager, W. (2010). Revised Pacific M-anomaly geomagnetic polarity time scale. Geophysical Journal International, 182(1):203-232, https://doi.org/10.1111/j.1365-246X.2010.04619.x.

46. Van Avendonk, H., Christeson, Gail., Norton, I., Eddy, D. (2015) Continental rifting and sediment infill in the northwestern Gulf of Mexico. Geology, 43(7):631-634, https://doi.org/10.1130/G367981 . 
47. van Hinsbergen, D.J.J., de Groot, L.V., van Schaik, S.J., Spakman, W., Bijl, P.K., Sluijs, A., Langereis, C.G., Brinkhuis, H. (2015) A Paleolatitude Calculator for

Studies,

PLOS

ONE, $\quad 10(6)$

e0126946,

https://doi.org/10.1371/journal.pone.0126946. 
590 Figure 1. Potential field maps of the Gulf of Mexico. (a) Original and (b) interpreted magnetic anomaly (on land: Lesur et al., 2016);

(c) Original and (d) interpreted vertical

592 gradient of gravity (Sandwell et al., 2014). Solid black lines, seafloor spreading magnetic

593 anomalies; solid red lines, fossil spreading axis and isolated segments; blue solid lines,

594 fracture zones; black dotted lines, continent-ocean boundary (COB). Numbers on land correspond to magnetic domains: Yucatán (1) and Florida (2) cratonic blocks, the Sierra Madre mountain range (3) and the basins fringing Louisiana and Texas (4).

Figure 2. Magnetic anomaly maps of the reconstructed Gulf of Mexico at the time of A) GoM2o ( 150 Ma), B) GoM2y ( 147), and C) GoM1y ( 140 Ma). The Yucatan Block is rotated with respect to fixed North America. Thick color line marks the spreading center, and colored star the Euler pole of the corresponding finite rotation. Color circles are constraining points for plate reconstructions. The dashed line delineates the Yucatan Block before rotation. The thick black line displays the continental part of Yucatan Block. Grey and black thin lines represent the initial and rotated coastlines, respectively.

Figure 3. Tectonic model for the evolution of the Gulf of Mexico. Solid black lines, seafloor spreading magnetic anomalies labeled in red; solid red lines, fossil spreading axis and isolated segments; blue solid lines, fracture zones; dotted black lines, continent-ocean boundary $(\mathrm{COB})$; color circles, constraining points for plate reconstructions; color stars,

608 Euler poles for finite (black contours, labelled F) and stage (no contour, labelled S) rotations.

609 Purple, COB pseudo-reconstruction; Blue and green, GoM2o-GoM2y and GoM2y-GoM1y

610 reconstructions. Blue and green lines represent computed flowlines for the corresponding 611 periods. Background colors show the vertical gradient of gravity (see Figure 1c).

612 Figure 4. Dating intermediate wavelength magnetic anomalies in the Gulf of Mexico. A)

613 Filtered geomagnetic polarity time scale (Malinverno et al., 2012) with, black line, original 
614 GPTS; blue and green lines, low-pass filtered GPTS retaining wavelengths higher than $3 \mathrm{Myr}$ 615 and 5 Myr, respectively. The GPTS has been inverted to take into account the configuration 616 of the Gulf of Mexico at the time of its opening. The red square marks the proposed 617 identification. B) Magnetic anomaly profiles extracted from the magnetic anomaly map of the 618 Gulf of Mexico (background) along five selected flowlines. The corresponding anomalies are 619 projected perpendicular to each profile, with different colors for clarity. C) Magnetic anomaly 620 profiles (red lines) and filtered GPTS (blue and green lines filtered as in A) showing the 621 proposed magnetic interpretation. Dark and light shades mark GoM1 and GoM2 anomalies, 622 respectively. Dotted black lines mark the fossil spreading axis and possible other fossil 623 spreading segments suggested by the vertical gradient of gravity. 


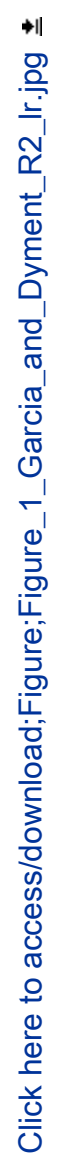
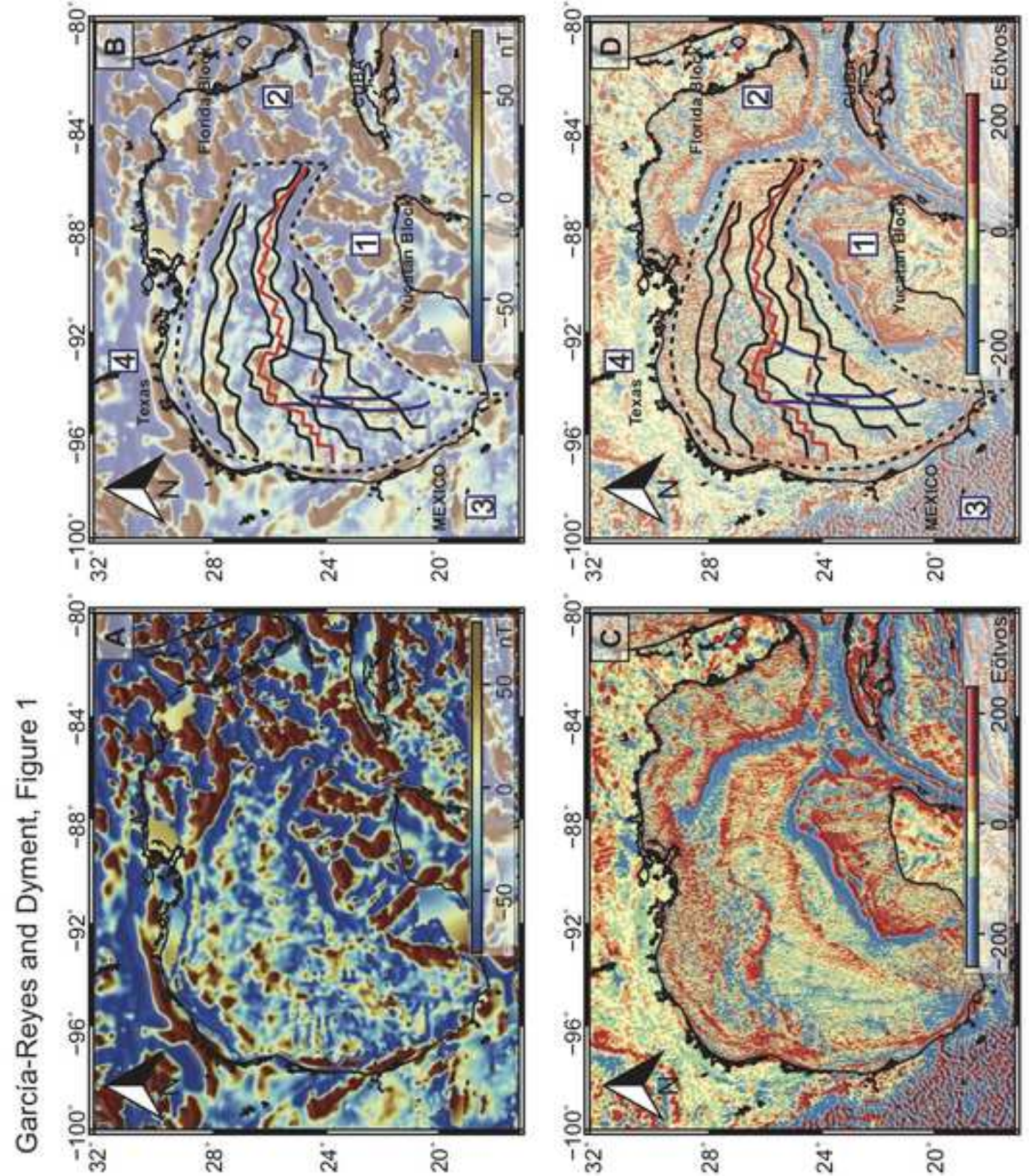

혼 
Figure 2

Click here to

access/download;Figure;Figure_2_Garcia_Dyment_R1.jpg

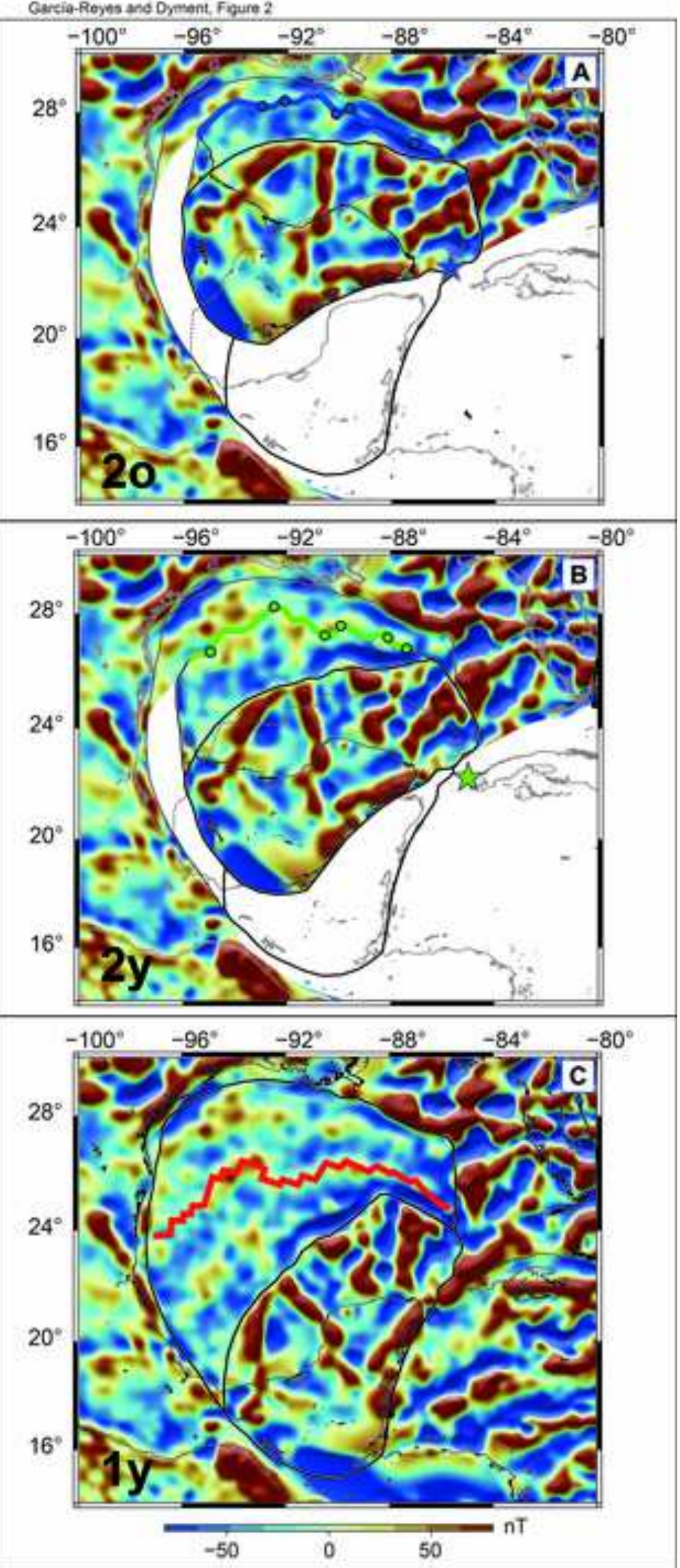




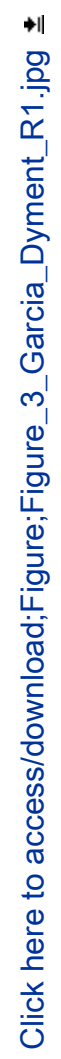

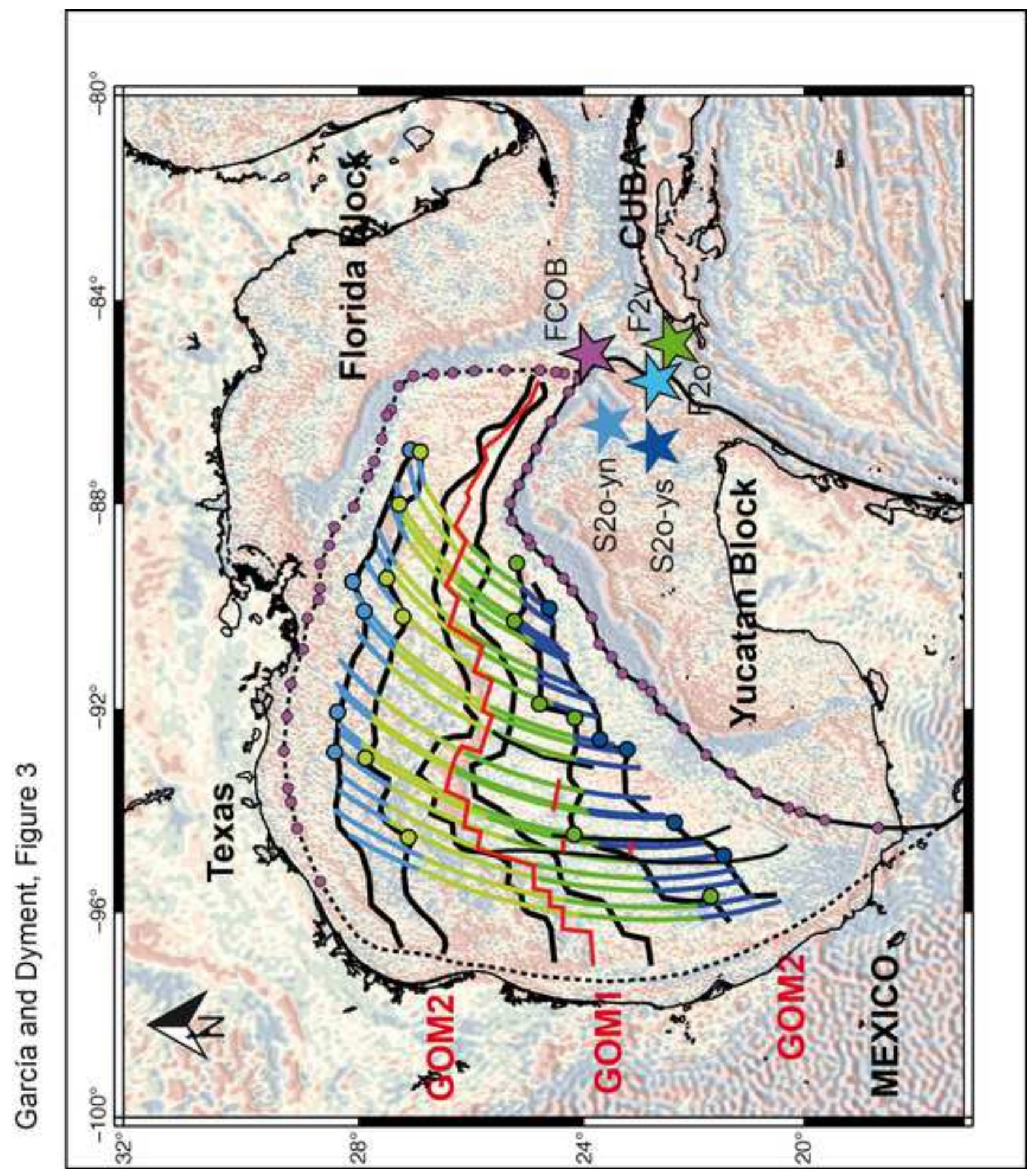

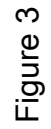




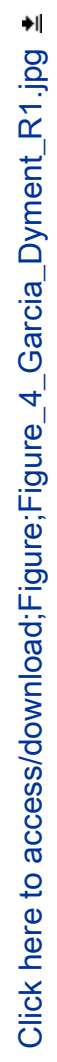
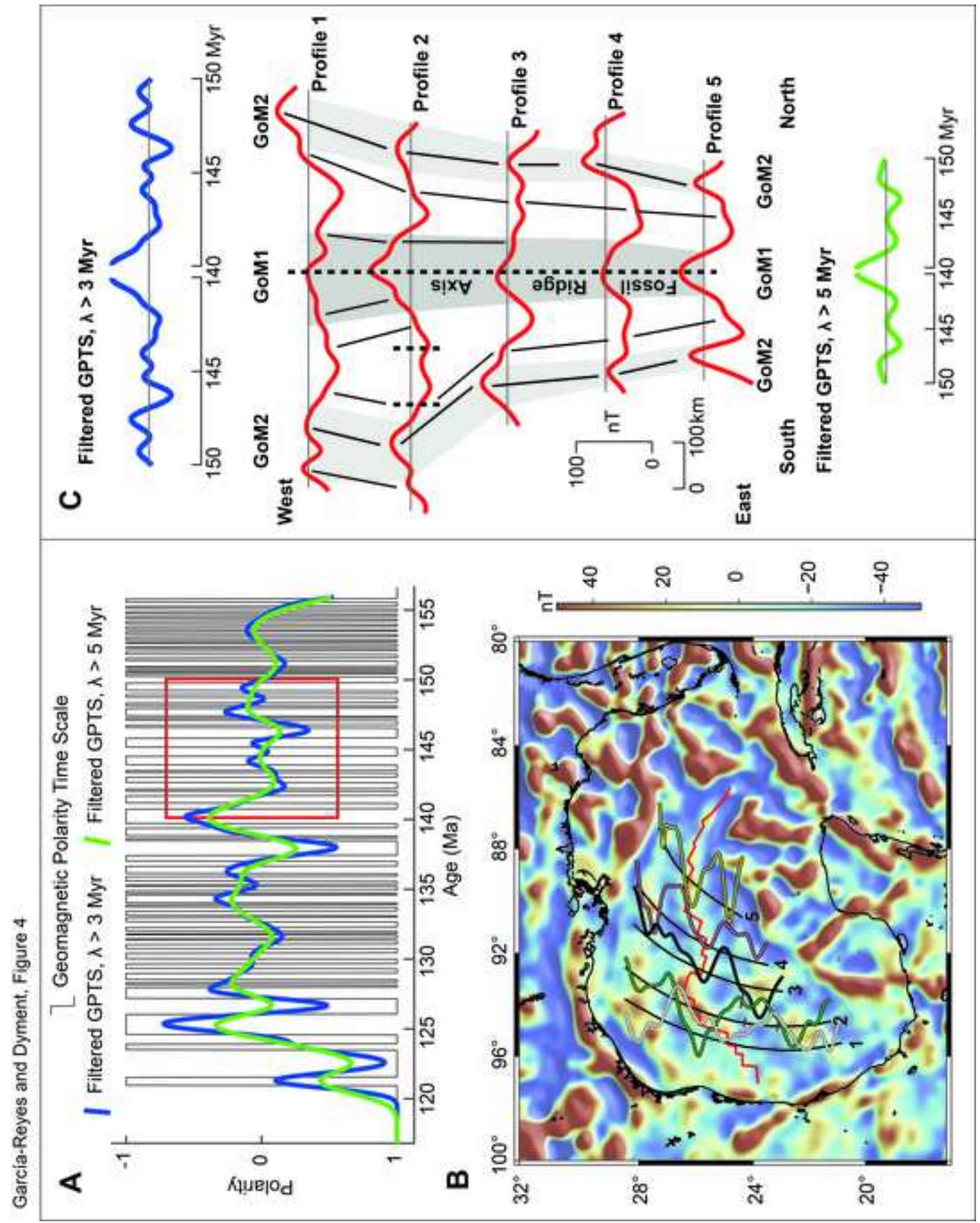

함 